\title{
GCU
}

Glasgow Caledonian

University

University for the Common Good

\section{Mössbauer and XRD study of hot dip galvanized alloy}

Kuzmann, E.; Speakman, R.; El-Sharif, M.; Stichleutner, S.; Hommonay, Z.; Klencsár, Z.; Sziráki, L.; Chisholm, C.U.; Lak, Gy. B.

Published in:

Hyperfine Interactions

DOI:

$10.1007 / \mathrm{s} 10751-016-1362-x$

Publication date:

2016

Document Version

Author accepted manuscript

Link to publication in ResearchOnline

Citation for published version (Harvard):

Kuzmann, E, Speakman, R, El-Sharif, M, Stichleutner, S, Hommonay, Z, Klencsár, Z, Sziráki, L, Chisholm, CU \& Lak, GB 2016, 'Mössbauer and XRD study of hot dip galvanized alloy', Hyperfine Interactions, vol. 237, 148.

https://doi.org/10.1007/s10751-016-1362-x

\section{General rights}

Copyright and moral rights for the publications made accessible in the public portal are retained by the authors and/or other copyright owners and it is a condition of accessing publications that users recognise and abide by the legal requirements associated with these rights.

Take down policy

If you believe that this document breaches copyright please view our takedown policy at https://edshare.gcu.ac.uk/id/eprint/5179 for details of how to contact us. 


\title{
MÖSSBAUER AND XRD STUDY OF HOT DIP GALVANIZED
}

\author{
ALLOY \\ E. Kuzmann ${ }^{\mathrm{a}}$, R. Speakman, ${ }^{\mathrm{b}}$ M. El-Sharif ${ }^{\mathrm{b}}$, S. Stichleutner ${ }^{\mathrm{a}, \mathrm{c}}$, Z. Homonnay ${ }^{\mathrm{a}}$, Z. Klencsár ${ }^{\mathrm{d}}$, \\ L. Sziráki ${ }^{\mathrm{a}}$, C.U. Chisholm ${ }^{\mathrm{b}}$ and Gy.B. Lak ${ }^{\mathrm{b}}$ \\ ${ }^{a}$ Institute of Chemistry, Eötvös Loránd University, Budapest, Hungary \\ ${ }^{b}$ Glasgow Caledonian University, Glasgow, Scotland, U.K \\ ${ }^{c}$ Nuclear Analysis and Radiography Department, Centre for Energy Research, HAS, \\ Budapest, Hungary \\ ${ }^{d}$ Institute of Materials and Environmental Chemistry, Research Centre for Natural Sciences, \\ HAS, Budapest, Hungary \\ e-mail of the corresponding author: kuzmann@caesar.elte.hu
}

\begin{abstract}
Mössbauer spectroscopy has been used to investigate the nature of the Zinc-Iron alloys present within the Hot Dip Galvanized (HDG) layers of steel with a silicon content of $0.35 \%$. The investigation also studied the impact of the powder coating pretreatment on the nature of the alloy layers. The acid etching process within the pretreatment process in particular would be expected to have a significant impact on the HDG layer. This study utilized ${ }^{57} \mathrm{Fe}$ Mössbauer spectroscopy to examine identically processed samples prior to and post pre treatment. XRD and ${ }^{57} \mathrm{Fe}$ CEMS measurements were performed on hot galvanized S355J2+N samples, forming sandwiched structure. Both XRD and CEMS reveal the presence of dominant steel phase in accordance with its estimated occurrence on the surface of the sandwiched samples. Minor $\Gamma-\mathrm{Fe} 3 Z n 10, \zeta-F e Z n 15$ and solid solution Fe-Zn as well as minor Fe-Si phases could also be identified.
\end{abstract}

\section{Keywords}

Hot dip galvanization, Iron-Zinc alloys, Mössbauer spectroscopy, X-ray diffraction

\section{Introduction}


The hot dip galvanizing (HDG) process is carried out on many steel components such as sculptures, railings, children's play parks, structural beams and automotive frames, creating corrosion protection both in the form of barrier protection and cathodic protection. HDG has been used as a process for over 150 years and is still an important process for corrosion protection of steel. Powder coating is added to galvanized steel for two main purposes; to improve aesthetic characteristics and to provide greater corrosion protection through the addition of a second barrier coating, which reduces the rate at which the zinc galvanized coating is consumed.

Pinholing and outgassing type surface defects have been reported on powder coating since the introduction of powder coatings in the early 1970s, with these surface defects being particularly prominent when the substrate is HDG steel [1]. These surface defects can result in a reduction in aesthetic quality and a reduction in the corrosion performance of the duplex coating, and are clearly undesirable in the final product, weakening performance in the working environments and causing increased costs in the manufacturing process. A study into the causes of pinhole defects on powder coatings on HDG steel identified many factors which can contribute [2]. One of the most significant factors identified is the alloy nature of the steel. The presence of silicon within steel has a significant impact on the nature of the zinc-iron alloys that are formed within the HDG coating $[3,4]$ depending on the Si content. Where silicon is present at levels of greater than $0.20 \%$ HDG coatings are non-uniform and abnormally thick. These thick HDG coatings are observed to provide problematic substrates for further processing, and are considered to contribute to pinholing and outgassing defects in powder coating.

In the present work XRD and Mössbauer spectroscopy has been used to investigate the nature of the Zinc-Iron alloys present within the HDG layers of steel with a silicon content of $0.35 \%$. The investigation also studied the impact of the powder coating pretreatment on the nature of the alloy layers. The acid etching process within the pretreatment process in particular would be expected to have a significant impact on the HDG layer. This study utilized ${ }^{57} \mathrm{Fe}$ Mössbauer spectroscopy to examine identically processed samples prior to and post pre treatment.

\section{Experimental}


There were 4 samples investigated (labelled 1, 2, $5 \&$ 6) which are all of galvanized $\mathrm{S} 355 \mathrm{~J} 2+\mathrm{N}$ steel, and were galvanized in a single production run (Table 1). Samples $1 \& 2$ were galvanized then fettled (mechanically smoothed using a grinder), samples $5 \& 6$ were processed in the same manner then underwent a powder coating pretreatment process. Thereafter the samples have been cut and formed into a sandwich structure to increase the relative amount of zinc/iron alloy interface within the sample. Figure 1 is a flowchart of the process routes the samples underwent.

TABLE 1 Characteristics of the samples

\begin{tabular}{|l|l|l|}
\hline Sample No & Name & Remark \\
\hline 1 & galvanized steel & $\begin{array}{l}\text { galvanized then fettled (mechanically smoothed using } \\
\text { a grinder) }\end{array}$ \\
\hline 2 & galvanized steel & $\begin{array}{l}\text { galvanized then fettled (mechanically smoothed using } \\
\text { a grinder) }\end{array}$ \\
\hline 5 & galvanized steel & $\begin{array}{l}\text { processed in the same manner then underwent a } \\
\text { powder coating pretreatment process }\end{array}$ \\
\hline 6 & galvanized steel & $\begin{array}{l}\text { processed in the same manner then underwent a } \\
\text { powder coating pretreatment process }\end{array}$ \\
\hline
\end{tabular}

The inspection certificate for the steel has the following compositional analysis depicted in Table 2.

TABLE 2. Composition of the steel (w\%)

\begin{tabular}{|l|l|l|l|l|l|l|l|}
\hline $\mathrm{C}$ & $\mathrm{Si}$ & $\mathrm{Mn}$ & $\mathrm{P}$ & $\mathrm{S}$ & $\mathrm{Cr}$ & $\mathrm{Mo}$ & $\mathrm{Ni}$ \\
\hline 0.14 & 0.35 & 1.36 & 0.013 & 0.008 & 0.022 & 0.002 & 0.026 \\
\hline $\mathrm{Al}$ & $\mathrm{Cu}$ & $\mathrm{Nb}$ & $\mathrm{B}$ & $\mathrm{Sn}$ & $\mathrm{Ti}$ & $\mathrm{N}$ & $\mathrm{V}$ \\
\hline 0.039 & 0.029 & 0.026 & 0.0001 & 0.002 & 0.002 & 0.005 & 0.005 \\
\hline
\end{tabular}




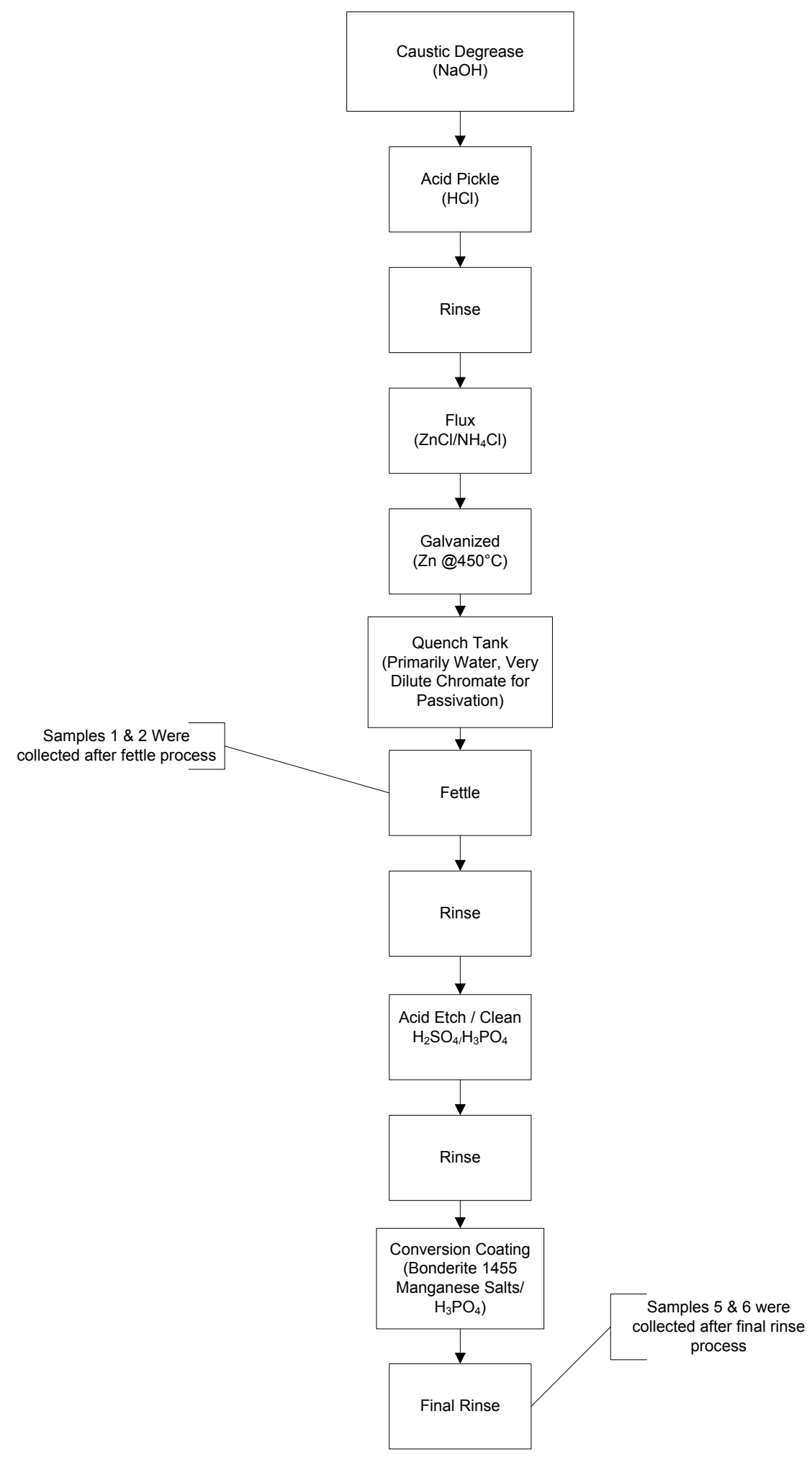

Figure 1. Process Routes for Samples 
SEM measurements and the EDX determination of the elemental composition were carried out with a FEI Quanta 3D high resolution scanning electron microscope.

Powder X-ray diffractograms of the samples were measured in Bragg-Brentano geometry using a DRON-2 computer controlled diffractometer (at $45 \mathrm{kV}$ and $35 \mathrm{~mA}$ ) using the $\beta$ filtered FeK $\alpha$ radiation $(\lambda=1.93735 \AA)$ at room temperature. The goniometer speed chosen was $1 / 4 \mathrm{deg} \mathrm{min}^{-1}$ in the range of $2 \Theta=20-120 \mathrm{deg}$. The diffraction patterns were evaluated using EXRAY peak searching software (developed by Z. Klencsár at the Eötvös University, 1996). For identification of the phases the ASTM X-ray Diffraction Data were used.

${ }^{57} \mathrm{Fe}$ conversion electron Mössbauer spectra of the samples were recorded with conventional Mössbauer spectrometers (WISSEL) working in constant acceleration mode at room temperature. The conversion electrons were detected by a flowing gas RANGER type detector using $\mathrm{He}-4 \% \mathrm{CH}_{4}$ gas mixture. A $50 \mathrm{mCi}$ activity ${ }^{57} \mathrm{Co} / \mathrm{Rh}$ source supplied the gamma rays for ${ }^{57} \mathrm{Fe}$ measurements. The velocity calibration was performed by $\alpha$-Fe measurement. The isomer shifts are given relative to $\alpha$-Fe. The evaluations of the Mössbauer spectra were made by least square fitting of Lorentzian lines using the MOSSWINN software [5].

\section{Results and discussions}

XRD of the samples are shown in Fig. 2. 

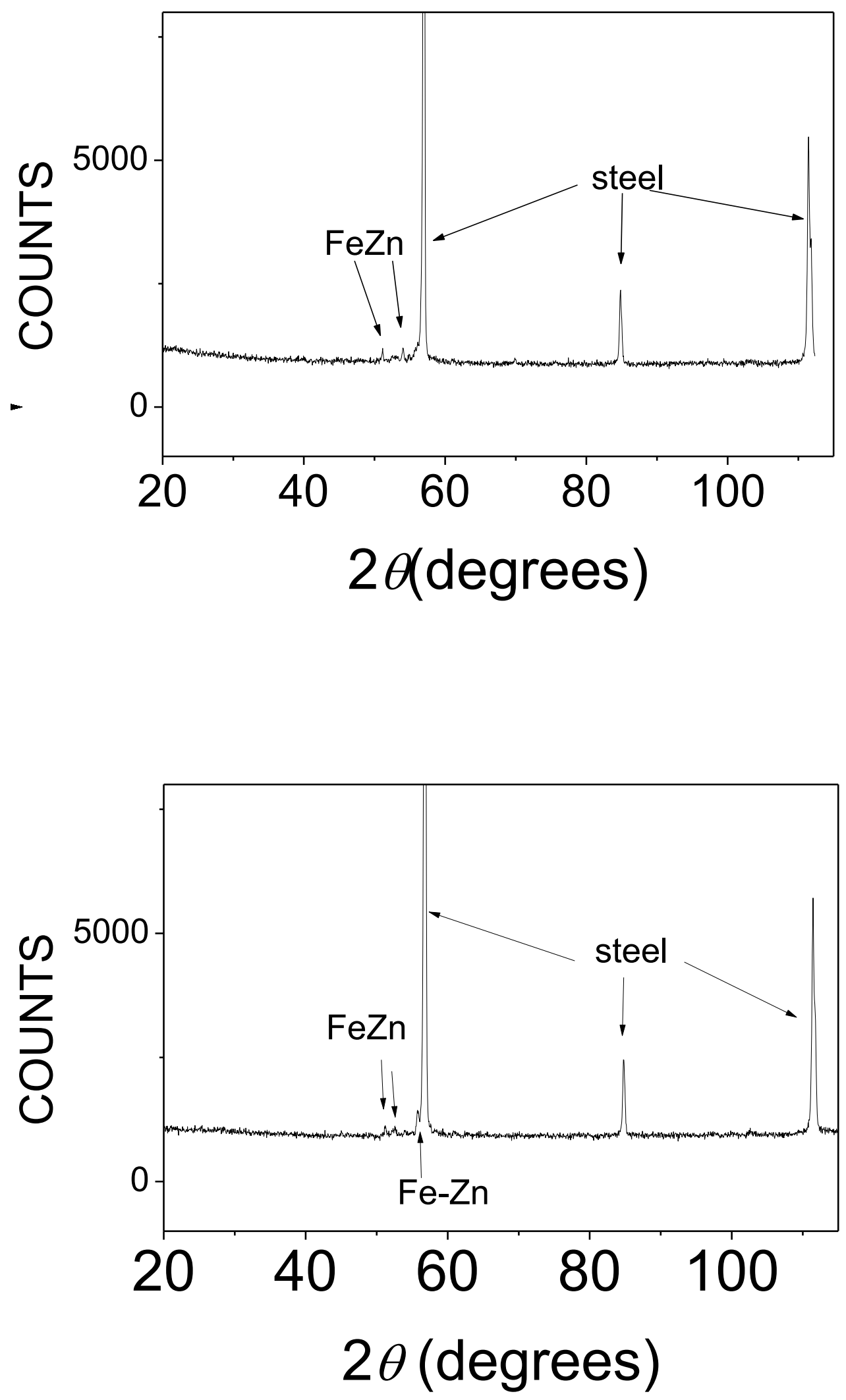

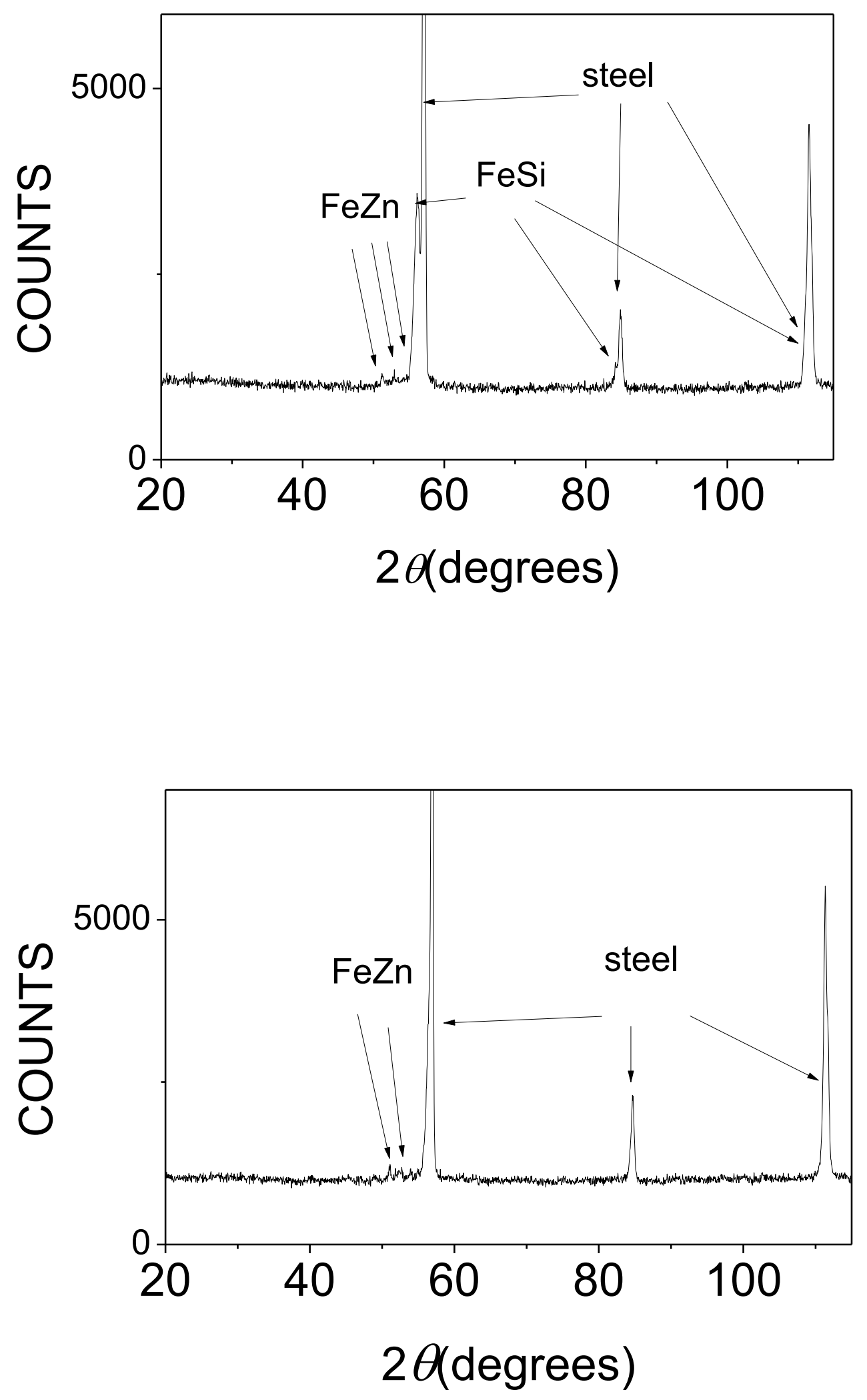
Fig. 2. XRD of sample No1, No2, No5 and No6, from top to the bottom with the assignment of the main reflections

The XRD diffractograms of all samples reflect the high intensity peaks of the steel. Besides the lines which belong undoubtedly to the reflections (011), (002) and (211) of steel, there are only very small intensity lines (except sample No5) in the diffractograms. These minor lines may be associated with $\Gamma-\mathrm{Fe}_{3} \mathrm{Zn}_{10}, \zeta-\mathrm{FeZn}_{15}, \mathrm{Fe}-\mathrm{Zn}$ solid solution and FeSi phases based on the match of the main lines corresponding to the phases in the standard ASTM cards and literature (ASTM 71-0399, 34-1314, 83-1259 and [6]). The (011) reflection of Fe-Zn solid solution at $2 \theta 55.75^{\circ}$ was used for the assignment in the case of sample No 2, although the other reflections were vanished probably due to a texture effect. This identification is suggested by the possible appearance of this phase in the corresponding Mössbauer spectrum of the sample. In the case of the diffractogram of sample No 5 there are present lines with relatively high intensity at $2 \theta 56.15^{\circ}, 84.20^{\circ}$ and $110.91^{\circ}$. These may correspond to a $\mathrm{Fe}-\mathrm{Si}$ phase (ASTM 83-1259) since the reflections are matched well to the literature values. However, the main intensity line can also overlap with the reflection corresponding to a $\mathrm{Fe}$ Zn solid solution.

Possible phase composition of samples based on the XRD measurements is presented in Table 3.

Table 3. XRD phase analysis

\begin{tabular}{|c|c|c|c|c|}
\hline Phases/Samples & No 1 & No 2 & No 5 & No 6 \\
\hline steel & major & major & major & major \\
\hline$\Gamma-\mathrm{Fe}_{3} \mathrm{Zn}_{10}$ & minor & very minor & very minor & minor \\
\hline$\zeta$-FeZn 15 & very minor & minor & minor & very minor \\
\hline $\begin{array}{l}\text { Fe-Zn solid } \\
\text { solution }\end{array}$ & $\begin{array}{l}\text { not } \\
\text { identified }\end{array}$ & minor & $\begin{array}{l}\text { not } \\
\text { identified }\end{array}$ & $\begin{array}{l}\text { not } \\
\text { identified }\end{array}$ \\
\hline
\end{tabular}




\begin{tabular}{|l|l|l|l|l|}
\hline FeSi & $\begin{array}{l}\text { can not be } \\
\text { excluded }\end{array}$ & $\begin{array}{l}\text { can not be } \\
\text { excluded }\end{array}$ & $\begin{array}{l}\text { intense } \\
\text { minor }\end{array}$ & $\begin{array}{l}\text { can not be } \\
\text { excluded }\end{array}$ \\
\hline
\end{tabular}

It is important to take into consideration that the penetration depth of the X-ray is around 25$30 \mu \mathrm{m}$ in the case of the powder XRD investigation of these samples, therefore the method gives an average information about the phase composition in this relatively wide layer.

The occurrence of $\Gamma$-Fe3Zn10 and $\zeta$-FeZn15 phases can be well accepted since these phases could be expected on the surface of samples due to the hot galvanisation procedure $[2,7]$. The occurrence of Fe-Zn solid solution phase could show that $\mathrm{Zn}$ can be incorporated into the Fe matrix.

The appearance of the considerable amount of Fe-Si solid solution phase in the sample No 5 may also be very interesting as a consequence of the high Si content of the steel. One could relate this to the powder coating pretreatment, but, the XRD result obtained with the sample No6, prepared in the similar way, does not support this conclusion.

Note, however, that the quantitative analysis by XRD for sample to sample is uncertain enough because of poor detectability of minor phases compared to the steel in our case when the sample surface, being perpendicular to the sandwich structure of coated layers, consisted of mainly the surface of the original steel.

${ }^{57}$ Fe Mössbauer spectra of the samples are shown Fig. 3. 

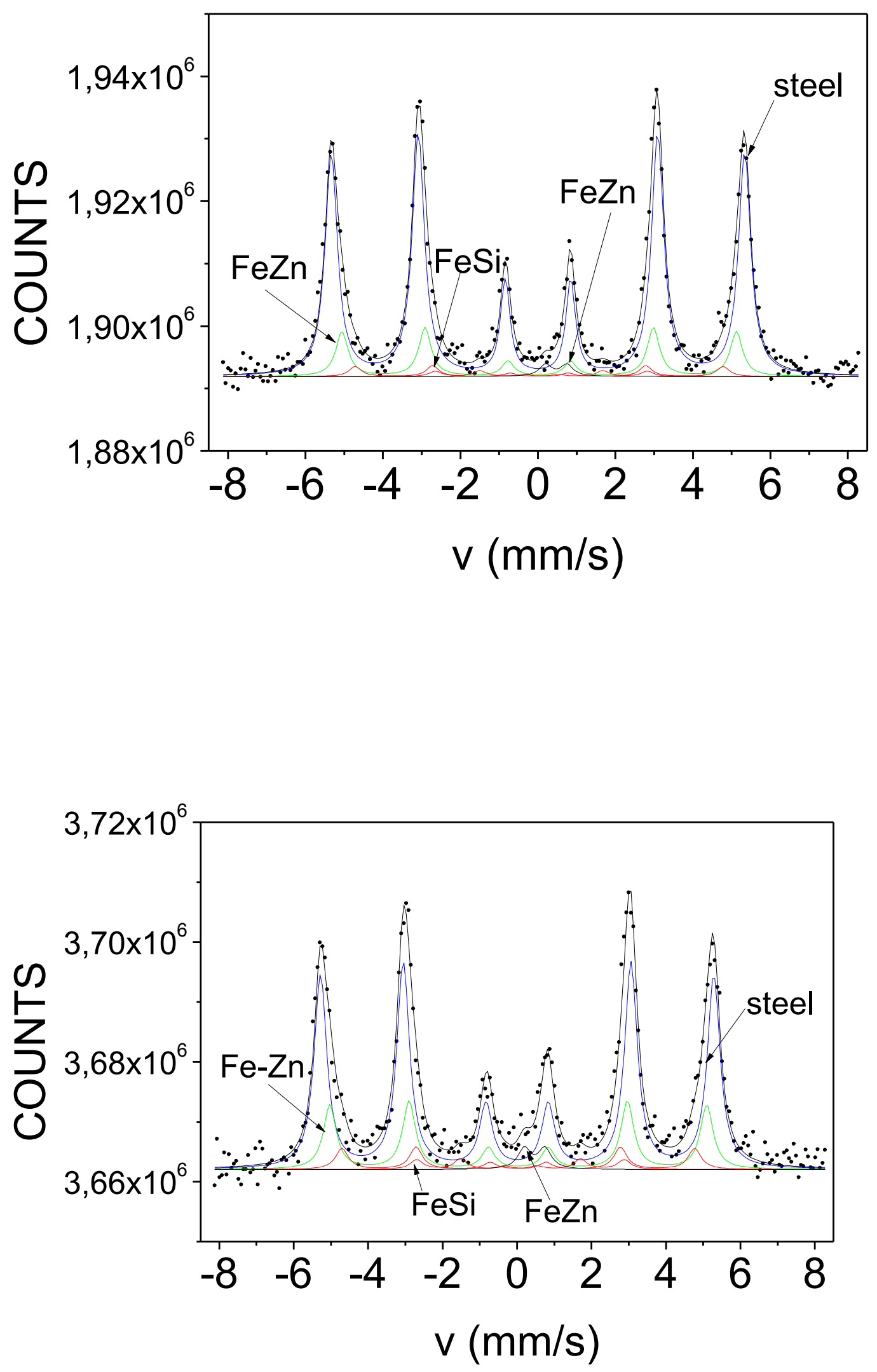

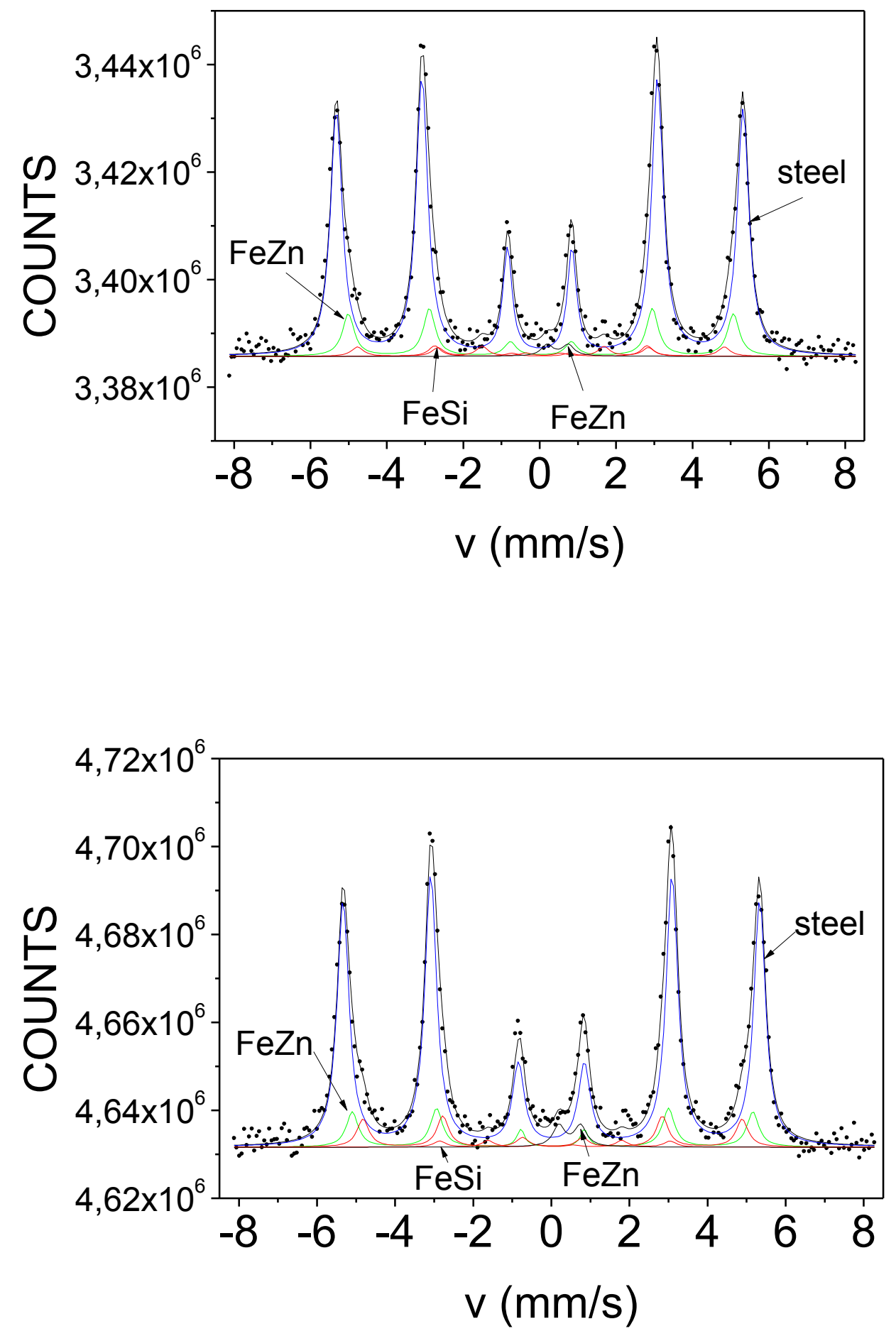

Fig. 3. ${ }^{57} \mathrm{Fe}$ CEM spectrum of sample No1,No2, No5 and No6, from top to the bottom with the assignment of the components 
The Mössbauer spectra of samples were evaluated under different constrains between the parameters and a-priori preconditions with several trials. The optimum fittings were found when the spectra of the samples were evaluated into 4 sextets and a doublet The assignment of spectral components can be based on the MERDI [8] and as well as the work of Cook et al. [9]. The doublet is assigned to FeZn phases like $\Gamma$ or $\zeta$ phases $[9,10]$. This is a minor component of all Mössbauer spectra with nearly same intensity under the present experimental conditions. The sextet with isomer shift $0 \mathrm{~mm} / \mathrm{s}$ and hyperfine field $33 \mathrm{~T}$ is the fingerprint of the steel [8]. This is the dominant component of all Mössbauer spectrum. The minor sextet with 31-32 $\mathrm{T}$ hyperfine field can be associated with the Fe- $\mathrm{Zn}$ solid solution alloy [6]. This can be recognised well mainly in the spectrum of sample No 2, where the $\mathrm{XRD}$ may also indicate the presence of this phase. The sextet having around 30T hyperfine field can be assigned to $\mathrm{Fe}-\mathrm{Si}$ phase $[11,12]$, which is a minor component, reaching its maximum in sample No5 where XRD may indicate the occurrence of a FeSi phase. Sextets with 17-18 $\mathrm{T}$ hyperfine fields can be also connected with $\mathrm{Fe}-\mathrm{Si}$ phase $[11,12]$. This is a minor component of all spectra, which does not show a significant fluctuation from sample to sample. The phase composition of samples based on the Mössbauer measurements is given in Table 4.

TABLE 4. Phase composition of samples based on the Mössbauer measurements

\begin{tabular}{|l|l|l|l|l|}
\hline Phases/Samples & No 1 & No 2 & No 5 & No 6 \\
\hline steel & major & major & major & major \\
& $76 \%$ & $65 \%$ & $79 \%$ & $76 \%$ \\
\hline$\Gamma-$ Fe $_{3} Z_{10}$ and & minor & minor & minor & minor \\
$\zeta-F e Z n_{15}$ & $2 \%$ & $3 \%$ & $2 \%$ & $3 \%$ \\
\hline $\begin{array}{l}\text { Fe-Zn solid } \\
\text { solution }\end{array}$ & minor & Intense minor & minor & minor \\
\hline FeSi & $16 \%$ & $22 \%$ & $13 \%$ & $11 \%$ \\
\hline
\end{tabular}

*The data indicate the relative spectral area of the corresponding components 
It is worth to take into consideration that ${ }^{57} \mathrm{Fe}$ conversion electron Mössbauer spectroscopy can only monitor a depth of about $0.1-0.3 \mu \mathrm{m}$ on the surfaces of samples. The method gives an average information about the phase composition. A very unfavourable geometry of samples was subjected for the investigation. The surface perpendicular to the sandwich structure consisted of mainly the surface of the original steel, which was well reflected by the Mössbauer spectroscopy. The 2-3 area \% of the occurrence of the $\Gamma$ and $\zeta \mathrm{Fe}-\mathrm{Zn}$ phases in the samples is in accordance with the expectation that such Fe-Zn phases are formed at the hot galvanisation process between the layers of the steel in the sandwich structure. The CEM measurements indicate a relatively high contribution of solid solution Fe- $\mathrm{Zn}$ phase in all investigated samples, although its relative occurrence is somewhat higher in the only fettled samples (No 1 and 2) than in which samples (No 5 and 6) powder coating pretreatment was also applied. The appearance of FeSi phase in 6-10\% may not be so very surprising in a steel of relatively high Si content.

\section{Conclusions}

PXRD and ${ }^{57} \mathrm{Fe}$ CEMS measurements were performed on hot galvanised S355J2+N steel (of $0.35 \mathrm{w} \% \mathrm{Si}$ ) content samples with sandwiched structure when the X-ray and $\gamma$-ray was applied parallel to the galvanised layers. This geometry is very unfavourable to get phase analytical information about the composition of galvanised layers by the applied methods.

Both XRD and CEMS reveal the presence of dominant steel phase in accordance with its estimated occurrence on the surface of the sandwiched samples.

FeZn minor phases $\left(\Gamma-\mathrm{Fe}_{3} \mathrm{Zn}_{10}\right.$ and $\left.\zeta-F e Z \mathrm{n}_{15}\right)$ near the detection limits of the applied methods were identified in all samples. This proves that these FeZn phases are formed during the hot galvanisation in agreement with the expectation. However, the accurate distinguishing and quantitative identification of the individual FeZn phases were very difficult and uncertain.

Solid solution Fe-Zn minor phase can be indicated by CEMS in all samples and by $\mathrm{XRD}$ in the case of sample No 2. 
Fe-Si minor phases can be identified by XRD in considerable amount in sample No 5 and by CEMS in less content in all samples. The occurrence of Fe-Si phases during the HDG can be well attributed to the relatively high Si content of the steel. The discrepancy between the results of phase analysis by CEMS and XRD may indicate inhomogeneous distribution of the phases along the depth.

The results of the phase analysis of samples prepared under same procedure (No1 and No 2 or No 5 and No 6) are not in the expected agreement. On the other hand, the phase analytical results of the samples (No 2 and No 6) prepared under different procedures are somewhat similar. Therefore it is hard to conclude for the effect of the powder coating pretreatment on the phase composition at the present stage of the study.

\section{Acknowledgements}

Financial support from the Hungarian National Research Fund (OTKA project No K68135 K115913) is gratefully acknowledged.

\section{References}

1. C. Haines, B. Bromley, Finishing. 17 (1993) 6.

2. P.G. Rahrig, Powder Coating (2004) 25.

3. N. Tang, Journal of Phase Equilibria and Diffusion. 29(4), (2008)337-344.

4. M. Bjordal, S. B. Axelsen, O. Ø. Knudsen, Progress in Organic Coatings 56 (2006) $68-75$

5. Z. Klencsár, E. Kuzmann, A. Vértes, J.Radioanal.Nucl.Chem. 210 (1996) 105.

6. A. Błachowski, K. Ruebenbauer, J. Żukrowski , J. Przewoźnik , J. Marzec , A. Rakowska, Journal of Physics and Chemistry of Solids 72(12), (2011) 1537-1542

7. J Nakano, D. V. Malakhov, G. R. Purdy, 29 (2005) 276-288. 
8. J.G. Stevens, V. Stevens, Mössbauer Reference and Data Index, 1966-1978. Plenum Press, New York.

9. D.C. Cook and R.G. Grant, Galvatech (1995) 508.

10. M. J. Graham, P. E. Beaubien, G. I. Sproule, Journal of Materials Science 15 (1980) 626-630.

11. M.B.: Stearns, Phys. Rev. 129(3), (1963) 1136-1144

12. F. B.Waanders - A. F. Mulaba-Bafubiandi, L Lodya, Hyperfine Interact, 226 (2014) $721-735$ 